sore-throats. Ordered lime-water spray, and internally sulpho-carbolate of lime. Evening: Pains gone; the throat the same. Temperature $102 \cdot 6^{\circ}$; pulse $126 .-27$ th (morning): Feels better; throat cleaning. Temperature $100^{\circ}$; pulse 100. Albumen one-sixth; no blood. Evening: Temperature $1008^{\circ}$; pulse $100 .-28$ th: Better, only weak; throat clean. Temperature $99.8^{\circ}$; pulse 98 . A trace of alburnen.-29th: Faint trace of albumen. Temperature $99^{\circ}$; pulse $9 \mathrm{l}$, not regular. Heart sounds normal. - 30th : Stronger; no albumen. Temperature $984^{\circ}$; pulse 84 , still slightly irregular. Tonics were prescribed. The patient now seemed convalescent, was recovering strength, and was placed at the window daily to inbale fresh air.-July 4th : Everything returned. Urine albuminous. Temperature $101 \cdot 8^{\circ}$; pulse 100, irregularity more marked. Thick yellowish membrane, like an elongated half-crown, over both tonsils \&c. terminating abruptly; tissues bordering it tumid and red. Spray \&c. resumed. Evening: In the same condition. Temperature $102^{\circ}$; pulse $90 .-5$ th (morning) : Throat cleaning. Albumen present. Temperature $99^{\circ} ;$ pulse 70. Evening : Temperature $100.8^{\circ}$; pulse 70.6 th : Pieces of membrane at circumference only. Albumen gone. Temperature $99.8^{\circ}$; pulse 70. - 7th: Better. No albumen. Throat clean. Temperature $994^{\circ}$; pulse 67 , still irregular. -8th: Better in every way. No albumen. Temperature \&c. normal; pulse the same. All went well, though strength was slowly gained. No sign of paralysis was ever noted, but the girl sometimes thought "food would return by the nose."

CASE 2.-J. H. A——, a short, slim lad of eight years and fair complexion, was admitted into the London Fever Hospital on Nov. 1st, 1882, having suffered from malaise and slight sore-throat for five or six days, and now complaining of increasing weakness. On the left tonsil was seen a -white patch the size of a shilling, of fair consistence, quite adherent, and with a well-defined margin; surrounding tissues red and slightly swollen. There were pain, tenderness, and some fulness at the angles of the jaws, especially the left jaw. Tongue furred; bowels confined. Temperature only slightly raised. Pulse good, regular, and . only slightly quickened; heart sounds normal. Respiration hurried, and accompanied by much hacking cough-both having well-marked laryngeal characters; air entering lungs very well. No cyanosis. He was ordered nourishing diet \&c., and the chlorine spray. - 4th: No membrane in throat; otherwise the same. Laryngeal symptoms still pror nounced.-8th : Boy bright and cheerful, but stridor \&e. worse. Has had three attacks of dyspnoea, a rather severe one last night at eleven o'clock, but it passed off and the lad slept peacefully. Albumen has appeared in the urine. Has been slightly sick. Ordered ten grains of ipecacuanha powder till sick. -9th : Sick after the first dose of ipecacuanha, but no membrane recognised in vomit. Passed a good night. 10 A.M. Reported to have just "had a spasm ; became blue, and almost choked." Found to be decidedly cyanotic and distressed; voice nearly gone; pulse rapid and feeble; boy mentally excited; air enters lungs badly-retraction; improved gradually. At about 10.30, another attack coming on, I immediately performed tracheotomy, a large quantity of membrane being coughed up. The boy improved at once, the pulse becoming slower, steady, and stronger. Flannels wrung out of hot water were laid over the tube, and limewater was sprayed directly over the tube at short intervals. 10th: General state excellent. No cyanosis. No sign of heart failure. Lungs healthy; breathing easy; much membrane is coughed up; and a thick creamy discharge exudes constantly from the wound and is coughed up.-12th: After this no more membrane as such was brought up, but the creamy discharge was most copious. - 16th : Discharge less and much thinner.-17th : Discharge little and watery. Some cough still and laryngeal voice. Tube removed; comfortable without it. Spray left off. Tonies ordered. -20th: No albumen; no sign of paralysis. Wound healthy. Got up. Towards the end of December the boy was discharged well, the wound being quite healed and represented by a scar three-quarters of an inch long by a quarter of an inch broad. This case is recorded to direct attention to what seems to me to be a solvent action of lime-water upon diphtheritic membrane. I now use the saccharated solution, and alternate it with an antiseptic Out of twenty cases so treated I have only lost one, and that due clearly to heart failure. I would also draw atten tion to the simplicity and efficiency of covering the tube lightly with a layer of flannel wrung out of hot water and frequently changed, thus avoiding scalding, damp bed, and other evils of tents and kettles. Some antiseptic also may be dropped on the flannel.

Warkton, Kettering.

\section{ON TWO RAPIDLY FATAL CASES OF DIPHTHERITIC PARALYSIS.}

\section{BY F. FOORD CAIGER, M.D. LoND., D.P.H. CAMB.}

THE fact that the great majority of cases of diphtheritic paralysis end in complete recovery has an undoubted tendency to make one under-estimate the danger which may underlie even the most trivial instance of the disorder. The following two rapidly fatal cases have served to emphasise this fact in my mind.

C. $\mathbf{R}-$, a gardener, aged twenty-five, was attacked on May 22nd with ordinary pharyngeal diphtheria. There was nothing noteworthy in the attack except that the membrane was somewhat unduly persistent, the tonsils not clearing till the thirteenth day. His temperature reached the normal on the ninth day. There was no albuminuria and but slight glandular implication, nor was the illness followed by undue prostration. After a few days in the country he resumed his employment.

On July lst, having finished his day's work, he again presented hinself, saying that he felt very unwell. The man was so obviously ill that he was at once readmitted to the hospital. According to his account he had never felt really strong or well since the illness. About six days previously he began to have difficulty in speaking plainly, and afterwards noticed that there was increasing difficulty in swallowing, the food often getting into the air passages or returning through the nose, with frequent fits of choking. Had felt numbness in the fingers and feet for the last two days, but was able to do his work, though greatly fatigued thereby. When admitted, at 6.30 P.M., it was extremely difficult to understand what he said, phonation being very imperfect and the voice hoarse and nasal. There was great difficulty in swallowing either liquids or solids, frequent shallow hoarse cough, with inability to clear his fauces. The vocal cords were seen to be lying in the cadaveric position, and moved but slightly towards the mid-line. The larynx was anæsthetic. Muscular power in arms weak, and tingling in feet. Patellar reflex exaggerated. Temperature $1036^{\circ}$; respiration 40, shallow and jerky. Pulse 120._-2nd: Passed a restless night. Complete inability to swallow; fed with soft stomach-tube. Voice inaudible. Repiration 48 , shallow and noisy. Diaphragm acting very feebly, if at all. Face dusky, sweating. Pulse 120 , regular. Patellar reflex absent. Analgesia in legs, but can feel cutaneous pressure During the afternoon the sweating continued; cyanosis became more marked. Pupils dilated. Respiration over 50, very shallow. Died quietly at 5.45 P.M. Twenty-four hours before his death the man was at work.

The second case occurred in a child aged five years. C. D- admitted on Aug. 28th with faucial diphtheria, complained of sore-throat and vomited the day before. The case was a severe one, characterised by abundance of exudation on tonsils and pharynx, much glandular swelling, rhinorrhœa, and great prostration. On Sept. 6th he had a severe syncopic attack, but rallied under stimulants. The membrane in this case, too, was very persistent, the throat not becoming free until the sixteenth day. The temperature reached the normal on the eighth day, and afterwards was usually subnormal. There was slight albuminuria from the first, which remained as a nearly constant trace throughout the illness. With the exception of some paralysis and loss of reflex in the palate and a certain amount of glandular swelling, the ensuing convalescence presented nothing unusual. On the 17 th it was noted that the voice had quite lost its nasal tone. On the 20th the patellar reflex disappeared; the palate was anæsthetic. No motor paralysis observed. On October 2 nd food was noticed to return through the nose. Palate immovable; no reflex. Bilateral ophthalmoplegia externa especially affecting the right internal rectus, which was quite paralysed. Accommodation sluggish ; irides react to light. Walk very "groggy"; patellar reflex absent. - 14th : Double ptosis, most marked on the left side. Albuminuria slight; child sitting up in bed playing with its toys.- 
15th : Inability to swallow; voice indistinct; dyspnoea. Ocular paralysis complete. The legs and back appear very weak; cannot support himself in a sitting posture. No resistance to passing the stomach tube. Diaphragm not acting; thoracic respiration feeble (40 to the minute); inability to cough ; restless and sweating ; pulse 100, regular. Towards evening cyanosis became marked. Temperature $99 \cdot 8^{\circ}$; respiration over 50 , shallow and noisy. Died at 11 P.M., the pulse being perceptible for some time after respiration had ceased.

It is remarkable that in both instances, although paretic symptoms were present for about a week before death, yet it was only within the last thirty-six hours that the cases took on a serious aspect and proved fatal by respiratory paralysis. The symptoms pointing to an affection of the vital functions occurred during the late stage of convalescence-viz, in the fifth and sixth week,-a time when it is more usual to find a form of paralysis mainly characterised by an affection of the spinal nerves supplying the limbs. In both cases the faucial affection was severe, the membrane being very persistent. This is in accord with my own experience-viz., that it is the severe cases which are most frequently followed by subsequent paralysis, the mild ones usually escaping altogether. I believe that in a good many cases of paralysis which are diagnosed to be of diphtheritic origin the original attack of diphtheria is accepted on insufficient evidence; the statement elicited from the patient or his friends that he has had a sore-throat some weeks previously (in one case I remember it was three months) being taken as sufficiently conclusive evidence that it was an attack of diphtheria, whereas the case might with equal propriety be referred to the operation of some other cause of which we are ignorant. Cases of peripheral neuritis of alcoholic origin may be the type of a wider series, and they certainly bear a close clinical analogy to diphtheritic paralysis.

I have been repeatedly struck by the fact that those cases of diphtheria which during the acute stage present a large amount of mucoid secretion at the back of the pharynx, accompanied with rhinorrhoea, are of the most grave kind, and rapidly reach a fatal termination. The increased secretion, however, is probably only apparent, the accumu. lation being due to retention, and is a sign of the oncoming paralysis of deglutition, which quickly becomes associated with laryngeal affection and cardiac or respiratory failure. It is this paralysis of early onset, affecting as it does the vital functions, which is so frequently fatal, and tends, I think, to support the view, adopted by Hilton Fagge on the theory of $a^{\text {" }}$ neuritis migrans," that there is direct association between the local process and an affection of the nuclei of origin or of the nerve trunks emanating from the medulla and floor of the fourth ventricle, from some of the peripheral fibres of which the diseased surface derives its innervation.

Fever Hospital, Hampstead.

\section{CASES OF LITHOLAPAXY IN CHILDREN.}

BY LEWIS W. MARSHALL, M.D., SURGEON to THE CHILDREN'S hospital, NOTTINGHAM.

THE following list of cases occurring in my practice may prove of service as an addition to those already published by others. The cases are taken in the order of their occurrence. The earlier operations were done at a time when it was extremely difficult to obtain lithotrites of the size required, owing to the great demand for them. As a result, some operations were ultimately completed by lateral lithotomy.

CASE 1.-W. H. WNov. 12th, 1887. The calculus was measured (?) by palpation, and believed to be about the size of the last phalanx of the index finger.-20th : Chloroform given. No. 5 lithotrite introduced, but considerable time was lost in endeavouring to catch the stone; twenty-seven grains only removed by one crushing. The boy being a good deal collapsed, it was deemed wiser to send him back to bed. Some bloody urine was passed, and the temperature rose for a day or two afterwards. Much more pain and straining. -28th : Chloroform again given. The same lithotrite introduced twice also a No. 6 evacuator. Four ounces of warm boracic lotion were injected before the introduction of the lithotrite. The buttocks were wuch more raised. This operation took forty minutes. The patient was sounded afterwards, but no piece was felt. - 30th : Got up, but had a slight rise in tem. perature afterwards.-Dec. 20 th : Went home.-July 25th, 1888: Readmitted with stone symptons. - Aug. 24th : Chloroform given, and a calculus was felt and crushed by a No. 5 lithotrite after two introductions. Operation lasted fifty minutes; sixty-four grains removed.-28th : Got up, having been quite free from pain or symptoms since the crushing.-Dept. 1st: Discharged cured.

CASE 2.-W. H- ten years of age, was admitted on Dec. $17 \mathrm{th}, 1887$, with a history of "stone" symptoms for three months. On Jan. 1st, 1888, a No. 6 lithotrite was passed, and the stone was readily caught. The calculus was then found to ve larger than had been previously estimated. The lithotrite strained in attempting to "crush," and was withdrawn with some trouble. A No. 10 evacuator had previously been introduced after slitting the urethra. No further attempt was made on this occasion, because the only lithotrite in hand was rendered useless. - 8th : A No. 10 lithotrite was lent by Messrs. Weiss, and attempts made to introduce it. This failed. Lateral lithotomy was therefore done. The stone was found in two halves; it weighed five drachms, and was very hard. This case did very well, and remains so.

CASE 3.-H. S- aged two years and a half, was admitted on May 19th, 1888, with a history of symptoms for two months. -28th: Sounded under chloroform, and stone gauged by palpation to be round and about the size of a hazel-nut. -29th: Chloroform given. A No. 6 evacuator passed; two ounces and a half of warm boracic lotion were injected into the bladder after withdrawing the urine. A No. 5 lithotrite was introduced, and the stone easily caught; it was soft and easily crushed, and almost entirely removed by the first introduction of the evacuator. The lithotrite was passed a second time and a small piece pulverised and afterwards removed by the same evacuator.-3lst: Got up and was quite well.

CASE 4.-G. A. GJune 2nd, 1888, with a history of three months' pain. 17th: The stone measured by palpation and believed to be about the length of the last phalanx of the index finger.2lst: Chloroform. A No. 9 evacuator was passed the first time. A No. 5 lithotrite was passed, but the stone being found to be hard and larger than was expected, an old: French lithotrite (the only one available) replaced it. A smaller evacuator had to be introduced on account of the swelling of the urethra. The boy became collapsed after the removal of 97 grains.--Aug. 24th: Lateral lithotomy done, and the remainder of the calculus removed; it weighed 226 grains, the sum total being 323 grains. The boy recovered quickly.

CASE 5.-E. C- aged two years and ten months, was admitted on Oct. 27th, 1888. He had always had difficulty in passing his urine.-Oct. 28th: Meatus found to be very. small; enlarged, therefore, under cocaine. - 30th: The symptoms being unrelieved, a sound was passed. A calculus was found and described in the following words-viz., "Flat, ovoid, and about an inch in length." "This opinion was formed by palpation.-Nov. 11th: Chloroform was administered. A No. 5 lithotrite could not be passed after slitting up the urethra still further. Lateral lithotomy was performed, and the boy did well. The calculus was found to be three-quarters of an inch long, ovoid, and with flattened surfaces.

CASE $6-\mathrm{H}$. WMarch 27th, 1889. Pain \&c. for two years. The calculus was measured by palpation, and described as flat, ovoid, and about an inch in size.-April 8th: A No. 9 evacuator was passed, and a No. 8 lithotrite afterwards. Boracic lotion was injected. Two crushings only were performed, The time occupied was thirty-seven minutes. Weight sixty-seven grains. - Nov. 11th : The boy sat up in bed; he had passed a.few pieces the day after the operation.13th: Was riding a rocking-horse in the ward.

CASE 7.-G. W - a a ed seven years, was admitted on Aug. 7th, 1889." Pain for one month only. The patient was sounded and stone felt to be "light and small."-14th: Chloroform was given and the urethra slit up. A No. 8 evacuator was introduced to inject boracic lotion. A No. 8 lithotrite was passed, and crushing completed in seven minutes. A No. 10 evacuator was introduced, and the whole stone removed; it weighed one scruple. The time occupied in performing the operation was twenty-seven minutes.-16th : Got out of bed.-17th : Discharged cured. 